\title{
Prevalence of adenomyosis as a co-morbidity in patients who underwent hysterectomy for other indications
}

\author{
Ratna Bulusu ${ }^{1}$, Payel Ray ${ }^{2, *}$, Abhilasha N. Kumar ${ }^{3}$, Sanghamitra $S^{4}$ \\ ${ }^{1}$ Professor and HOD, Department of Obstetrics, East Point College of Medical Sciences and Research Centre, Bengaluru, \\ Karnataka, ${ }^{2}$ Associate Professor, ${ }^{3,4}$ Junior Resident, Department of Obstetrics, MVJ Medical College and Research Hospital, \\ Bengaluru, Karnataka, India \\ * Corresponding Author: \\ Email: roy_payel@yahoo.com
}

\begin{abstract}
Introduction: Adenomyosis is a common gynaecological condition that affects women of reproductive age group (20\%-60\%). The cardinal clinical features of adenomyosis are menorrhagia, dysmenorrhea and uterine enlargement. Classically, it was thought and compared with ultrasonography; MRI enables more accurate diagnosis of the disease when adenomyosis is suspected.

Objective: To evaluate the clinical profile associated with adenomyosis, frequency distribution and to determine the prevalence of adenomyosis in patients undergoing hysterectomy for other indications, as well as to correlate clinical examination with histopathological examination.

Methodology: It is a retrospective observational study which included 100 patients who underwent abdominal hysterectomy or vaginal hysterectomy for various indications. Age, parity, presenting complaints, elicited signs, indication for hysterectomy, and HPE report of the specimens were analyzed. All cases diagnosed as Adenomyosis and Endometriosis was excluded.

Results: Among 100 women who underwent hysterectomy, Adenomyosis was found in 24 cases (24\%). Menorrhagia (91.7\%), chronic pelvic pain (83.3\%), dysmenorrhea (79.2\%), dyspareunia (16.7\%) is the classic presentation. More common in multiparous women and begins later in reproductive life (mean age- 45yrs). (45.8\%) had bulky uterus on per vaginal examination. Adenomyosis was present in 10 of 23 patients (43.47\%) diagnosed as dysfunctional uterine bleeding; 6 of 24 (25\%) with fibroid; 4 of 21 (19.04\%) with prolapse; 2 of $14(14.28 \%)$ with ovarian mass; 2 of $10(20 \%)$ with pelvic inflammatory disease.

Conclusion: The prevalence of unsuspected adenomyosis is found to be $24 \%$ in this study. Adenomyosis is common in women presenting with chronic pelvic pain, menorrhagia and dysmenorrhea. It is also common in multiparous women with bulky uterus and mean age being 45 years. In women with completed family and had failed medical therapy given for undiagnosed Adenomyosis the choice of therapy is hysterectomy.
\end{abstract}

Keywords: Adenomyosis, Hysterectomy, Histopathological examination, HPE.

\section{Introduction}

Adenomyosis is a common gynaecological condition that affects the reproductive women. ${ }^{1}$ It is a condition where there is ingrowth of the endometrium, both the glandular and stromal components, directly into the myometrium. Uterine enlargement, dysmenorrhea and menorrhagia are regarded as the cardinal clinical features of adenomyosis. ${ }^{2-4}$

Various diagnostic modalities such as ultrasound and MRI are available to diagnose adenomyosis but the final diagnosis is obtained by naked eye examination of the cut specimen (Fig. 1) and histopathology (Fig. 2) of the same.

It is relatively frequent in multiparous women, in their fourth and fifth decade of life. ${ }^{5}$ Risk factors for adenomyosis are age, multiparity, surgical disruption of the endometrial-myometrial border, elevated levels of both FSH and prolactin, smoking habits and history of depression. ${ }^{6,7}$ Clinical diagnosis of adenomyosis is challenging because symptoms closely mimic those of other uterine pathology such as fibroid uterus, endometriosis or endometrial polyps. ${ }^{8,9}$

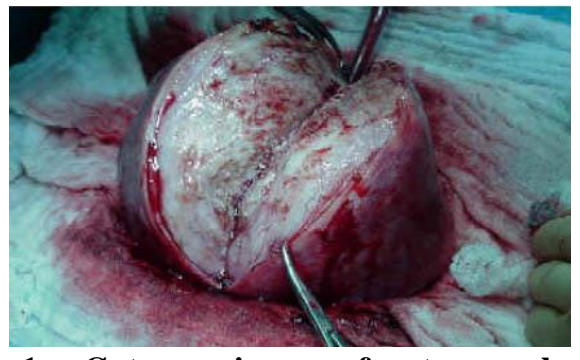

Fig. 1: Cut specimen of uterus showing myohyperplasia and adenomyosis

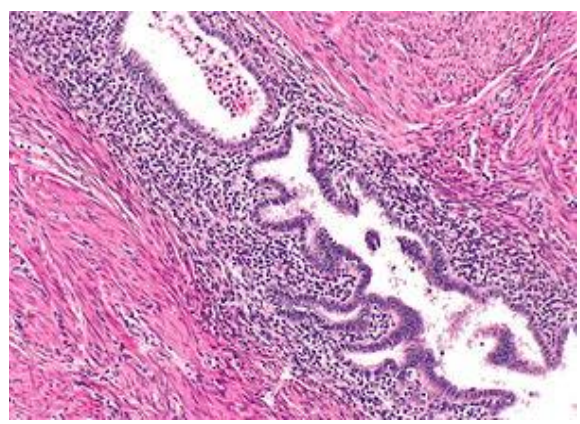

Fig. 2: HPE showing uterine Adenomyosis 
Oral contraceptive pills, gonadotropin hormones, progesterone pills, progesterone intrauterine devices are the main stay of medical treatment of symptoms as uterus is a hormonally responsive organ. Though they reduce the uterine symptoms of adenomyosis, it returns quickly after the medicine wears off. ${ }^{11,12}$ Complete eradication of deep adenomyosis is problematic and leads to treatment failure. Success rates varied widely for uterine artery embolization which was used to relieve symptoms for some women. ${ }^{13}$ The purpose of this study is to evaluate the clinical profile associated with adenomyosis, frequency distribution and to determine the prevalence of adenomyosis in patients undergoing hysterectomy for other indications, as well as to correlate clinical examination with histopathological report.

\section{Methodology}

A Hospital based observational study conducted in the department of Obstetrics and Gynaecology, MVJ medical college and hospital, Bangalore, India. Study included 100 patients who underwent abdominal or vaginal hysterectomy with or without salpingooophorectomy for various indications.

Age, parity, presenting complaints (Heavy menstrual bleeding, Dyspareunia, Dysmenorrhea, Chronic pelvic pain), elicited signs, indication for hysterectomy, and HPE report of the specimens were analyzed.

All cases diagnosed as Adenomyosis and Endometriosis was excluded.

The data was compiled in a standardized case record form for 100 subjects and statistical analysis was done.

\section{Results}

A total of 100 women underwent hysterectomy for various indications of which $78 \%$ underwent total abdominal hysterectomy and $22 \%$ underwent vaginal hysterectomy. Adenomyosis was diagnosed in 24 of 100 cases $(24 \%)$ by histopathological examination (HPE). All women were multiparous and the mean age of adenomyosis was 45 years. $30(30 \%)$ women had failed medical treatment history prior to surgery.

Table 1: Age distribution of patients who underwent hysterectomy and the frequency distribution on Adenomyosis

\begin{tabular}{|l|c|c|}
\hline $\begin{array}{c}\text { Age Distribution } \\
\text { (In Years) }\end{array}$ & Total & $\begin{array}{c}\text { Adenomyosis } \\
\text { Present }\end{array}$ \\
\hline$\leq 30$ & $(\mathbf{n = 1 0 0 )}$ & $\mathbf{( n = 2 4 ) ( \% )}$ \\
\hline $31-40$ & 2 & 0 \\
\hline $41-50$ & 32 & $7(29.16 \%)$ \\
\hline$>50$ & 45 & $13(54.16 \%)$ \\
\hline
\end{tabular}

Majority of the patients with adenomyosis (13 patients i.e. $54.16 \%$ ) were in the age group of 41-50 years.

Table 2: Indications for hysterectomy and the frequency distribution of Adenomyosis

\begin{tabular}{|l|c|c|}
\hline \multicolumn{1}{|c|}{ Indication } & Total & $\begin{array}{c}\text { Adenomyosis } \\
\text { Present }\end{array}$ \\
\hline & $(\mathbf{n = 1 0 0 )}$ & $\mathbf{( n = 2 4 ) ( \% )}$ \\
\hline $\begin{array}{l}\text { Dysfunctional } \\
\text { Uterine Bleeding } \\
\text { (DUB) }\end{array}$ & 23 & $10(43.47 \%)$ \\
\hline Fibroid Uterus & 24 & $6(25 \%)$ \\
\hline Uterine Prolapse & 21 & $4(19 \%)$ \\
\hline Ovarian Tumor & 14 & $2(14.28 \%)$ \\
\hline $\begin{array}{l}\text { Pelvic } \\
\text { Inflammatory } \\
\text { Disease (PID) }\end{array}$ & 10 & $2(20 \%)$ \\
\hline Others & 8 & $0(0 \%)$ \\
\hline
\end{tabular}

Highest incidence: Out of 23 patients who underwent hysterectomy for DUB, 10 (43.47\%) cases had a coexistent adenomyosis.

Lowest incidence: Out of 10 patients who underwent hysterectomy for PID, 2 (20\%) cases had a coexistent adenomyosis.

Table 3: Parity in patients with adenomyosis

\begin{tabular}{|c|c|}
\hline Parity & $(\mathbf{n = 2 4}) \mathbf{( \% )}$ \\
\hline 0 & 0 \\
\hline 1 & $1(4.16 \%)$ \\
\hline 2 & $8(33.53 \%)$ \\
\hline 3 & $10(41.66 \%)$ \\
\hline 4 & $3(12.5 \%)$ \\
\hline$\geq 5$ & $2(8.33 \%)$ \\
\hline
\end{tabular}

Adenomyosis is more common in multiparous women.

Table 4: Clinical symptoms of patients with HPE diagnosed adenomyosis

\begin{tabular}{|l|c|}
\hline \multicolumn{1}{|c|}{ Symptoms } & $(\mathbf{n = 2 4 ) ( \% )}$ \\
\hline $\begin{array}{l}\text { Abnormal Uterine } \\
\text { Bleeding (AUB) }\end{array}$ & $22(91.66 \%)$ \\
\hline Chronic Pelvic Pain & $20(83.33 \%)$ \\
\hline Dysmenorrhea & $19(79.16 \%)$ \\
\hline Dyspareunia & $4(16.66 \%)$ \\
\hline Pelvic Pressure & $9(37.5 \%)$ \\
\hline
\end{tabular}

As it is seen in Table 4, there was overlapping of symptoms; the highest incidence being AUB (91.66\%) and the next being chronic pelvic pain $(83.33 \%)$.

Table 5: Size of uterus in patients with Adenomyosis

\begin{tabular}{|c|c|}
\hline Size of Uterus & $(\mathbf{n = 2 4 ) ( \% )}$ \\
\hline Normal & $5(20.83 \%)$ \\
\hline Bulky & $11(45.83 \%)$ \\
\hline 6 weeks & $1(4.16 \%)$ \\
\hline 8 weeks & $4(16.66 \%)$ \\
\hline
\end{tabular}




\begin{tabular}{|c|c|}
\hline 10 weeks & $2(8.33 \%)$ \\
\hline$>10$ weeks & $1(4.16 \%)$ \\
\hline Total & $\mathbf{2 4}(\mathbf{2 4 \%})$ \\
\hline
\end{tabular}

$45.83 \%$ of the patients diagnosed histopathologically as Adenomyosis, had bulky uterus.

Table 6: Histopathology of the endometrium in patient's coexistent Adenomyosis

\begin{tabular}{|l|c|}
\hline \multicolumn{1}{|c|}{ Endometrial Changes } & $(\mathbf{n = 2 4 )} \mathbf{( \% )}$ \\
\hline Proliferative phase & $10(41.66 \%)$ \\
\hline Secretory phase & $6(25 \%)$ \\
\hline Senile atrophy & $4(16.66 \%)$ \\
\hline Endometrial hyperplasia & $3(12.5 \%)$ \\
\hline Disordered endometrium & $1(4.12 \%)$ \\
\hline Total & $24(24 \%)$ \\
\hline
\end{tabular}

The most common endometrial change in hysterectomized patients was proliferative type of endometrium $(41.66 \%)$.

\section{Discussions}

Hysterectomy is a definitive treatment of pelvic pathology including abnormal uterine bleeding, fibroid uterus, chronic pelvic pain, adenomyosis, endometriosis, pelvic inflammatory disease, uterine prolapse and genital malignancies. ${ }^{14}$

Adenomyosis uteri has been shown as a separate entity in the etiologies of AUB as classified by the following acronym PALM-COEIN. ${ }^{15}$ The most common preoperative indication in our study was menorrhagia (43.47\%), similar to study done by Rather et al. ${ }^{16}$ Deeksha Pandey et al ${ }^{17}$ and Vaidya and Vaidya ${ }^{18}$ had fibroid uterus as the commonest preoperative diagnosis i.e. $39.8 \%$ and $42.94 \%$ respectively.

Due to its vague symptoms adenomyosis is rarely diagnosed preoperatively. However, radiological modalities like transvaginal ultrasound and MRI are helpful. MRI is expensive and hence its access is limited. In our study, adenomyosis was the most common (24\%) incidental finding, similar to study done by Siwatch ${ }^{19}$ et al $(18.9 \%)$.

In this study data demonstrates that adenomyosis is a common finding in middle aged women and is present in almost one- fourth (24\%) of hysterectomy specimens. As it has no special symptoms of its own it was rarely diagnosed correctly preoperatively and is still largely underdiagnosed. $5-70 \%$ is the frequency found in literatures. In clinical observation chronic pelvic pain, menorrhagia and dysmenorrhea are thought to be suggestive of and attributable to the presence of adenomyosis. ${ }^{10}$ In this study data demonstrates that these three symptoms were most frequently related with adenomyosis. Parazzini F, et al reported that women with adenomyosis did not have dyspareunia but had more chronic pelvic pain and dysmenorrhea. ${ }^{6}$
Bergholt $\mathrm{T}$ et al reported that endometrial hyperplasia had a significant association with adenomyosis. Our study found more of proliferative type of endometrium in hysterectomy specimen with adenomyosis. $^{20}$

\section{Conclusions}

Adenomyosis is a clinical challenge. Nevertheless, the possibility of this lesion needs to be kept in mind while evaluating the patient. The prevalence of unsuspected adenomyosis is found to be $24 \%$ in this study. Adenomyosis is common in women presenting with chronic pelvic pain, menorrhagia and dysmenorrhea. It is also common in multiparous women with bulky uterus and mean age being 45 years. In women with completed family and had failed medical therapy given for undiagnosed Adenomyosis the choice of therapy is hysterectomy.

\section{References}

1. Tamai K, Koyama T, Umeoka S, Saga T, Fujii S, Togashi K. Spectrum of MR features in adenomyosis. Best Practice and Research. Clin Obstetr Gynaecol. 2006:20(4):583-602.

2. Bird C, McElin T, Manalo-Estrella P. The elusive adenomyosis of the uterus revisited. Am J Obstetr Gynecol. 1972;112(5):583-93.

3. Mehasseb MK, Habiba MA. review adenomyosis uteri: an update. The Obstetr Gynaecol. 2009;11:41-7.

4. Bergholt T, Eriksen L, Berendt N, Jacobsen M, Hertz JB. Prevalence and risk factors of adenomyosis at hysterectomy. Human Reprod. 2001;16(11):2418-21.

5. Kunz G, Beil D, Deininger H, Wildt L, Leyendecker G. The dynamics of rapid sperm transport through the female genital tract: evidence from vaginal sonogram of uterine peristalsis and hysterosalpingoscintigraphy. Human Reprod. 1996;11(3):627-32.

6. Parazzini F, Mais V, Cipriani S, Busacca M, Venturini P; GISE. Determinants of adenomyosis in women who underwent hysterectomy for benign gynecological conditions: results from a prospective multicentric study in Italy. Eur J Obstet Gynecol Reprod Biol. 2009;143(2):103-6.

7. Taran FA, Weaver AL, Coddington CC, Stewart EA. Understanding adenomyosis: a case control study. Fertility and Sterility. 2010;94:1223-8.

8. Kepkep K, Tuncay G, Göynümer, Tutal E. Transvaginal sonography in the diagnosis of adenomyosis: which findings are most accurate? Ultrasound in Obstetr Gynecolol. 2007;30:341-5.

9. Meredith SM, Ramos LS, Kaunitz AM. Diagnosticaccuracy of transvaginal sonography for the diagnosis of adenomyosis: systematic review and metaanalysis. Am J Obstetr Gynecol. 2009;201-107.e1-6.

10. Vercellini P, Ragni G, Trespidi L, et al. Adenomyosis: a deja vu? Obstet Gynecol Surv .1993;48:789-94. [Pubmed]

11. Ozaki T, Takahashi K, Okada M, Kurioka H, Miyazaki $\mathrm{K}$. Live birth after conservative surgery for severe adenomyosis following magnetic resonance imaging and gonadotropin-releasing hormone agonist therapy. Int $\mathbf{J}$ Fertil Womens Med 1999 Sep-Oct;44(5):260-4. [Pubmed]

12. Fedele L, Bianchi S, Raffaelli R, Portuese A, Dorta M Treatment of adenomyosis-associated menorrhagia with 
a levonorgestrel-releasing intrauterine device. Fertil Steril. 1997 Sep; 68(3):426-9. [Pubmed]

13. Lohle PN, De Vries J, Klazen CA, Boekkooi PF, Vervest HA, Smeets AJ,etal. Uterine artery embolization for symptomatic adenomyosis with or without uterine leiomyomas with the use of calibrated tris-acryl gelatin microspheres: midterm clinical and MR imaging followup. J Vasc Interv Radiol 2007 Jul;18(7):835-41.

14. Pervez SN, Javed K, Obald M. Hysterectomy: a clinicopathological correlation. KJMS 2014;7(2):295-297.

15. Malcolm G. Munro, Hilary O.D.Critchley, Michael S.Broder \& Ian S.Fraser. FIGO classification system (PALM-COEIN) for causes of abnormal uterine bleeding in nongravid women of reproductive age. Int. J. Gynecol. Obstet; 2011;113(1),3-13

16. Rather GR, Gupta Y, Bardhwaj S. Patterns of lesions in hysterectomy specimens: a prospective study. JK Science 2013;15(2):63-68.

17. Pandey D, Sehgal K, Saxena A, et al. An audit of indications, complications and justification of hysterectomies at a teaching hospital in India. International Journal of Reproductive Medicine 2014; ID 279273

18. Vaidya S, Vaidya SA. Patterns of lesions in hysterectomy specimens in a tertiary care hospital. JNMA 2015;53(197):18-23.

19. Siwatch S, Kundu R, Mohan H, et al. Histopathologic audit of hysterectomy specimens in a tertiary care hospital. Sri Lanka J Obstet Gynaecol 2012;34(4):155158.

20. Bergholt T, Eriksen L, Berendt N, Jacobsen M, Hertz JB. Prevalence and risk factors of adenomyosis at hysterectomy. Hum Reprod 2001;16:2418-21.

21. Siddegowda MS, Sandhu JK, Shivakumar S. Clinicopathological correlation of morphological lesions in hysterectomy specimens - A 3-year study in a medical college hospital. J. Evid. Based Med. Healthc. 2016; 3(51), 2592-2597. DOI: 10.18410/jebmh/2016/570

22. Shrestha A, Shrestha R, Sedhai LB, Pandit U.

Adenomyosis at hysterectomy: prevalance, patient characteristics, clinical profile and histopathological findings. Kathmandu Univ Med J 2012;37(1):53-6. 